3. Daze, A.- “Ein Beitrag zur Statistik der Farbenblindheit," Centralbl. f. prakt. Augenheilk., 1878, p. 79.

4. Favre. - "Résumé des mémoires sur la Daltonisme." Académie des Sciences, I877.

5. De Fontenay, O. E.- "Ueber die Farbenblindheit in Dänemark." Ibid. 1879, p. I35.

6. Franke, E.- "Ueber einige Ergebnisse vergleichender Farbensinnprüfungen." Archiv für Augenheilk., I9I I, Vol. LXXXII, p. I.

7. Guyer, M. F. - "Accessory Chromosomes in Man," Biol. Bull., Vol. XIX, p. 4. IgIO.

8. Hirschberg. - "Geschichte der Augenheilkunde im Altertum." Graefe-Sämisch, Vol. XII, p. I9I.

9. Holmgren, F.- "Ueber die Farbenblindheit in Schweden." Centralbl. f. prakt. Augenheilk., 1878, p. 201.

10. Jeffries, Joy. - "Colour Blindness, its Dangers and its Detection," Boston, I879.

I I. Köllner, H.- “Ueber Uebergänge zwischen normalem Farbensinn und angeborener Rotgrünblindheit." Arch. f. Augenheilk., Vol. LXXVIII.

12. Malling, B. - "Om Farvesans." Norsk Magasin f. Laegevidenskaben, I9I8, p. I.

13. Mendel, Gregor. "Versuche über Pflanzenhybriden." Verhandlungen des naturfor- . schenden Vereins in Brunn I865. Vol. IV., p. 34-7.

"Ueber einige aus künstlicher Befruchtung gewonnene Hieracium-Bastarde." Ibid. Vol. VIII., p. 26-3I.

14. Meyer.-British Journal of Psycliol., Vol. II, p. 36r (1908).

15. Mohr, Otto L. - "Om kjönnets bestemmelse og nedarving." Norsk Mag. f. Laegev. I916.

"Bidrag til spörsmaalet om yttre faktorers indvirkning paa kjöuscellerne." Ibid. I9I7.

I6. Parsons, J. H.- "An Introduction to the Study of Colour Vision."

17. Rivers, W. H. R.- "Observations on the Senses of the Todas." British Journal of Psychoiogy, Vol. I, p. 321 (1905).

18. Schiötz, H.- "Ophthalmometrische und optometrische Untersuchungen von 969 Augen." Arch. für Augenheilk., Vol. XVI.

19. Schiötz, H. - Trans. of the Ophthalmological Society Christiania, Nov. 19I7.

20. Schiötz, I. - Tidsskrift for Militaer Medicin, 1918, p. I37.

21. Schmitz, A. - "Statistische Mitteilungen über das Vorkommen von Farbenblindheit in Cleve und Umgebung." Centralbl.f. prakt. Augenheilk., 1880, p. 275.

22. Wilson, Edmund. "The Sex Chromosomes." Arch. f. mikr. Anatomie, Vol. LXXVII, I9II.

23. Wilson, George. - "Researches on Colour-Blindness," Edinburgh, I 855.

24. De Winiwarter.-" Etudes sur la spermatogenèse humaine." Arch. de Biolog., Vol. XXVII.

25. Wolfe, R. - "On Colour-Sight and Colour-Blindness in relation to railway and seasignals." Lancet, 1879, Vol. II, p. 23.

(To be continued.)

DR. EDRIDGE-GREEN'S THEORIES OF VISION

(continued)

$\mathrm{BY}$

J. Herbert Parsons, LONDON.

\title{
III._Colour Names
}

Dr. Edridge-Green divides the spectrum into "psycho-physical units." Thus, the normal person sees six colours-red, orange, yellow, green, blue and violet. Only a few persons see an additional 
colour, indigo; between the blue and the violet. A further subdivision is into "absolute psycho-physical units," according to the number of monochromatic patches which can be distinguished in the spectrum.

$\mathrm{He}$ says that colour blind people have fewer psycho-physical units, and may therefore be classified according to the number of colours seen into penta-, tetra-, tri-, and di-chromics. The dichromics see only two colours-red and violet; the trichromics three-red, green, and violet; the tetrachromics four-red, yellow, green, and violet; the pentachromic five-red, yellow, green, blue, and violet; the hexachromic six-red, orange, yellow, green, blue, and violet.

Dr. Edridge-Green's actual words are (p. 178) : “One man will declare that there is no difference in colour over the whole spectrum, but simply variations in brightness; another will say that the spectrum is tinged with red at one end and violet at the other, the central portion of the spectrum being colourless; another, that the spectrum consists of two colours, red and violet, with a small colourless interval; another, that the spectrum contains three colours, namely : red, green, and violet, the orange and yellow regions being designated red-green, and the blue region green-violet. Another will say that he sees four definite colours; others, five or six, and a few, seven." The matter is, however, not quite so simple as this statement implies. The colour blind are not consistent in the manner in which they name the colours of the spectrum. For example, an individual will often call the bright orange green if patches of the spectrum are shown passing in the direction from red to violet, but he will immediately afterwards call the same colour orange or reddish-yellow in passing from violet towards the red end. Many other examples of a similar nature might be cited.

Yet, in determining the class to which any person belongs, Dr. Edridge-Green attaches much importance to the names given to the colours. Now it has always been held hitherto that little importance is to be attached to the names given to colours by the colour blind, and there is good reason for the utmost caution in this respect. From the psychological point of view most people will agree with Hering that there are only four fundamental colours (excluding black and white), viz., red, yellow, green, and blue. The other colours in the spectrum can be analysed subjectively into these or mixtures of two of these colours, e.g., orange arouses the sensations of both red and yellow, and there are similar transition colours, which have not received distinctive names, between yellow and green, and green and blue. Of orange, Dr. Edridge-Green says, " to me orange is most definitely a fundamental sensation. I cannot see any trace of either red corresponding to the ruby glass or yellow in pure orange. I am quite unable to analyse orange 
into red and yellow and the term reddish-yellow does not describe orange "to me" (Physiology of Vision, p, 169). I do not think that this is the experience of most people with normal colour vision.

Now, let us suppose for the sake of argument, that colour blind people are really divided into dichromics, trichromics, etc., as Dr. Edridge-Green postulates. Such a person is born into the world with, for example, only two colour sensations. He sees all sorts of gradations of red and violet in various degrees of brightness and saturation. He learns, however, from intercourse with other people that these people have many colour names. Although he can see little or no difference in -colour between a strawberry and a strawberry leaf, he finds one is called red, the other green. He, therefore, learns to use all these names, though it must be very difficult for him to know why colours similar to him are called by different names under different circumstances.. So long as he is dealing with objects which are characteristic in shape or other attributes, he will probably use the right colour names; but if he is confronted with the colour divorced from these attributes, e.g., a circular patch of coloured light, he is likely to make mistakes. His sole adventitious guide in this case is the brightness of the light. According to most observers, though Dr. Edridge-Green differs from the generally accepted views (vide infra), in the majority of the colour blind there is a definite relationship between their appreciation of colours and the brightness of the lights. In one class, for example, reds look much less bright to them than to the normal person. They are, therefore, accustomed, in the absence of other adventitious aids, to call very dull lights red.

Hence, in naming the colours of the spectrum, the colour blind, though having fewer colour sensations than the normal, are accustomed to use several or all of the names in general use. Consequently they make egregious mistakes. Now, these mistakes appear to the onlooker to be quite meaningless. It is only after prolonged experience that the colour names used by the colour blind are found to possess a certain degree of consistency; but, at best, the names given to the colours are a very uncertain criterion of the type of colour blindness. That with increasing knowledge of this difficult subject they will attain greater value as indicators cannot be doubted; many difficulties in this direction have already been cleared up by the Young-Helmholtz theory (Cf. paper by $\mathrm{H}$. Hartridge in the last number of this Journal).

When we look at the question of colour names from another point of view they become of paramount importance, viz., when it becomes a question of deciding whether a colour blind person is likely to be dangerous as an engine driver, etc. Here, if a man calls green red, or vice versa, it is obvious, without any further evidence 
of the exact nature of his colour defect, that he is unfitted for such an occupation.

So far as colour names are concerned, then, I consider that they are a very unstable foundation for the scientific classification of various types or degrees of colour blindness. If we examine Dr. Edridge-Green's records of dichromics (pp. 186-189), we find that, though he says they are all dichromics, the colour names which the individuals used varied from 2 to 6 , excluding such names as redgreen, blue-green, etc. . Dr. Edridge-Green says (p. 179) that thisapplying different colour names to the various divisions of the spectrum - " only occurs when the examinee has some idea of the region presented to him." I do not think that most examiners would agree with this view.

Further evidence of the difficulty of the colour blind in naming colours is given by their invention of terms like red-green and green-violet. The former is not uncommon, but I do not remember myself to have heard the latter. Now red-green to me, and I imagine to most people, is meaningless, except in so far as experience has taught that its use is a sign of colour blindness. Dr. EdridgeGreen's views on "red-green " and yellow are rather obscure. He says (p. 141) "It is, however, much more probable that the effects of a mixture of red and green are not actually the same as those of a simple yellow, but are physiologically indistinguishable, the retino-cerebral apparatus not being sufficiently developed. The sensation yellow having replaced that of red-green of former ages the two have become indistinguishable. The physical and mathematical aspects of this point of view have been shown in a a very able paper by Houstoun. A corollary to this point of view is that when the colour sense has been still further developed a mixture of red and green will no longer match a simple yellow but will appear as a distinct colour in the same way as a mixture of red and violet make a perfect match with green for the dichromic, but the normal sighted readily distinguish one as green and the other as purple."

\section{IV.-Discrimination of Hue}

Dr. Edridge-Green, after dividing the spectrum into "psycho-physical units," according to colour names, further subdivides it into "absolute psycho-physical units" according to the number of monochromatic patches which the individual can discriminate. For this purpose he has devised the colour-perception spectrometer. It is used as follows :- " The observer should first ascertain the exact position of the termination of the red end of the spectrum, the left-hand shutter being moved across until every trace of red just disappears. The position of the pointer on the left-hand drum is noted, and the wave-length recorded. The left drum is 
then moved so that the shutter is more towards the middle of the spectrum. The right-hand drum is then moved until the pointer indicates the wave length recorded as the termination of the red end of the spectrum. The observer then moves the left hand shutter in and out until he obtains the largest portion of red, which appears absolutely monochromatic to him, no notice being taken of variations in brightness, but only in hue. The position of the index on the left hand drum is recorded. The left-hand shutter is then moved more towards the violet end of the spectrum, the right hand shutter being placed at the position previously occupied by the left-hand shutter. In this way the whole of the spectrum is traversed until the termination of the violet end of the spectrum is finally ascertained with the right-hand shutter."

The object of this instrument is to determine the smallest monochromatic patches into which the spectrum can be divided. I think it is not difficult to prove that in reality it measures the largest monochromatic pàtches.

The mind is so constituted as to appreciate relatively sudden change in sensations, not gradual change. By very gradual increase or decrease of temperature a frog may be boiled or frozen to death without making the smallest movement. Moreover, the successive is more easily and earlier apprehended than the simultaneous, for simultaneous sensations have a tendency to fuse. No more perfect method of obtaining the maximum fusion could be found than that of viewing simultaneously the perfect gradations of colour in the spectrum. When more delicate methods are used totally different results are obtained, as has been repeatedly proved-notably by König and Dieterici, Uhthoff, F. Exner, Steindler, and William Watson. Lord Rayleigh stated that he could distinguish between the wavelengths included in a monochromatic division to the extent of discriminating between the colours of the two D lines (Proc. Roy. Soc., B., 1910, Vol. LXXXII, p. 458). Dr. Edridge-Green traversed this statement and attributed the error to "the admixture of small quantities of white and coloured light and to certain physiological influences" (Proc. Roy. Soc., B., 1911, Vol. LXXXIV, p. 116). Dr. William Watson conclusively disproved any such influence of admixture with white light (Proc. Roy. Soc., B., 1911, Vol. 84, p. 118), and found that 14 observers gave the following mean values with sodium light: Width of monochromatic patch $=4.5 \mu \mu$; difference in wave-length easily detected as a change in hue= $1.4 \mu \mu$. The evidence against the validity of Dr. Edridge-Green's method for discriminating differences of hue in the spectrum is overwhelming. (See my "Introduction to the Study of Colour Vision," p. 30.)

I think, however, that the observations made with the spectrometer might afford valuable data for statistical enquiry. The 
classification of the number of maximal monochromatic patches of a considerable number of colour blind people might be expected to give evidence in favour of some definite grouping of the colour blind. It does not appear to me to give very strong support to Dr. Edridge-Green's grouping. For example, his 3 examples of trichromics have 10 monochromatic patches (p. 198), whereas in his examples of dichromics the numbers vary from 2 to 11 (pp. 186-9). Hexachromics are said to have 18 (p. 202), and tetrachromics 10 to 14 (p. 201).

\section{V.-Colour Mixture}

"All the colours of the spectrum and of nature can be imitated by mixtures of three selected spectral colours, so that in this sense colour vision is undoutedly trichromatic". (p. 136). This statement-which, however, is not strictly accurate-shows that Dr. Edridge-Green accepts the fundamental fact of colour mixtures, upon which the Young-Helmholtz or three-components theory is chiefly based.

Such a striking feature of colour vision demands a precise explanation from any comprehensive theory, yet little is said about it in Dr. Edridge-Green's latest book. In his Hunterian Lectures (1911, p. 23) he says: "We must therefore explain in another way the apparent trichromatism of normal colour vision, which is so well known to every photographer, especially those who are concerned with colour photography. If my theory of the evolution of the colour sense be the correct one, and we have cases of colour blindness corresponding to every degree of the evolutionary process, we have an explanation of the facts. In past ages all saw the rainbow made up of only three colours-red, green and violet. When a new colour (yellow) appeared between the red and green, it is obvious that a mixture of red and green would give rise, not to red-green, but to to the colour which had replaced it-namely, yellow." This does not appear to me to be a satisfactory or in any sense a complete explanation, and we have already seen (this Journal, p. 330) that Houstoun is in a similar difficulty.

It is true that more than three spectral colours will also explain the facts of colour mixtures. Thus, Bayliss (Principles of General Physiology, 1918, p. 524), a supporter of Dr. Edridge-Green, says : "The Young-Helmholtz theory assumes that there are only three primary colour sensations, red, green and violet. Now, while it is true that any colour may be formed by mixtures of these in appropriate proportions, it is also true that more than three primary sensations would also serve the same purpose, three is, in fact, the minimum." In this connection may I refer Prof. Bayliss to another passage in his book (p. 66)? "It seems to me that the well known principle of logic called "William of Occam's Razor" 
may legitimately be applied to such a case as the one before us: "entia non sunt multiplicanda praeter necessitatem." "Sir William Hamilton (1853) gives a more complete form in his "Law of Parsimony":: thus, "Neither more, nor more onerous, causes are to be assumed than are necessary to account for the phenomenon." So far as colour mixtures are concerned, more than three colours are "praeter necessitatem," but I am not prepared to deny. that the three-components theory does not account for all the facts of colour vision.

\section{VI.-The Yellow Sensation}

It is of fundamental importance to Dr. Edridge-Green that he should prove yellow to be a simple sensation and not the combined effect of stimulation of red and green sensations. $\mathrm{He}$ has dogmatically stated 16 propositions (pp. 141-146) in favour of the simple character of the yellow sensation; and the reader might well be led to think that there are no arguments on the other side, for none indeed are referred to. Yet this has already been a battle-ground of the Young-Helmholtz and Hering combatants, and was most carefully investigated by Burch, a very unbiassed observer.

Thus, Dr. Edridge-Green says:- "The eye may be fatigued for red and green without altering the hue of spectral yellow" (p. 143).

Burch (Phil. Trans., B, CXCI, 1898) says that in red fatigue the red end is shortened, but the green " appears with full intensity at (the) $D$ (line) and reaches more faintly almost as far as (the) $C$ (line)" (loc. cit., p. 6). "The eye, blinded for red, sees pure green from about $\mathrm{E}$ to $\mathrm{D}$ or even almost to $\mathrm{C}$ " (loc. cit., p. 15). In green fatigue "the green disappears, but its place is occupied by the red and blue, which not only meet, but overlap" (loc. cit., p. 6). Burch confirmed these observations on 70 people (loc. cit., p. 19). In another place (The Ophthalmoscope, Vol, XI, 1913, p. 145) Burch says:- " "It is a matter of every day demonstration in the laboratory that, using moderate stimuli, with persons of normal colour sensation, yellow does change to green after fatigue to red and to red after fatigue to green. And I am bound also to note that persons whose green sensation is weak fail to see this change in the colour of yellow after fatigue."

Dr. Edridge-Green: "If the eye be fatigued with pure spectral yellow light the spectrum will appear to have lost its yellow, and though yellowish-red or yellowish-green will appear less yellow, the terminal red of the spectrum will not be affected " (pp. 142-3).

Burch : Fatigue with orange or yellow affects not only the appearance of the orange or yellow, but that of the red or green also. "With light from $\mathrm{C}$ the effect upon the green is very marked, and it is evident that in the fatigue produced by light from $\mathrm{D}$, the red and the green colour sensations are about equally involved. After a very brief exposure to light of this wave-length the spectrum, 
although visible from $A$ to $K$, is seen to be uniformly dulled from A to $b$, the red appearing brick-red, the green yellowish and dingy. $A$ more protracted exposure to the light abolishes the red and green sensations altogether." (Phil. Trans., loc. cit., p. 8). Attention may be directed to the plates which accompany Burch's paper, showing the appearances of the spectrum after fatigue with spectral rays.

Dr. Edridge-Green: If the intensity of spectral yellow be gradually reduced, "the yellow becomes whiter and whiter until it becomes colourless, but does not change in hue" (p. 143). "There is no change in tone in pure yellow or pure blue as the intensity is diminished" (p. 170).

Burch (Proc. Roy. Soc., B. 76, 1905, p. 214) : "It follows that a colour like that of the sodium flame which, to a normal eye, excites the red and green sensations in almost equal proportions will, if the intensity is greatly reduced and the eye sufficiently rested, excite a larger proportion of green. This I have put to the test of experiment. The results are interesting as bearing on the precautions necessary in such cases .... But in the spectroscope .... the sodium lines appeared pale green when of the minimum visible intensity." (The italics are in the original).

Dr. Edridge-Green : "Spectral yellow after colour adaptation to green still appears yellow and not red" (p. 144). This is directly opposed to Burch's results. After sunlight from E, "which seems to correspond very nearly with the point of maximum sensitiveness to green . . . . if the slit is narrow the spectrum seems to consist of two colours only, namely, orangechrome and ultramarine, passing into each other through a neutral tint very difficult to describe. . . . . But on opening the slit the orange changes to a brilliant scarlet, reaching almost up to the blue, with only a narrow band of neutral tint between, and the violet is also plainly differentiated from the blue as in the normal spectrum. . . . . By simply opening or closing the slit the change can be effected at any time during the duration of greenblindness, showing that the orange hue of the red is due to the admixture with it of a subjective green (the positive after-effect), the intensity of which is a function of the time and not of the width of the slit at the moment, and which is therefore unnoticed when the brightness of the spectrum is sufficiently increased." (Phil. Trans., loc. cit., pp. 8-9).

Dr. Edridge-Green : "The after-image of pure spectral yellow is first seen as a bright yellow positive after-image; this does not change to green on becoming negative" (p. 144).

Burch : "The positive after-effect of light from between D and C is at first red. But it comprises two dazzle-tints red, and green, of which red soon vanishes, leaving green." (Phil. Trans., loc. cit., p. 7). 
Burch states definitely: "I have entirely failed, though I have sought it carefully, to detect any physical evidence of a separate sensation of yellow." (Phil. Trans., loc. cit., p. 16). Sir William Abney and many other observershave arrived at the same conclusion. Whether they are right or wrong it is unjustifiable for Dr. EdridgeGreen to convey the impression that his arguments are unassailable.

\section{VII.-The relationship of Colour and Brightness in the Colour blind}

According to Dr. Edridge-Green (Proc. Rov. Soc., B. 82, 1910, p. 458, and elsewhere) light perception and colour perception are quite distinct, and cases of colour blindness ean be divided into two classes, according as the defect is one of light perception, or one of colour perception or differentiation without any defect in light perception. Both defects may be present in the same individual. "Abnormalities and defects of light perception may be subdivided as follows: (1) Increase or diminution in the visible range of the spectrum. (2) Defective sensibility for certain wavelengths. (3) Increased sensitiveness for certain wave-lengths. (4) Variations in the maximum of the luminosity curve. Increase or defect in the power of dark adaptation (a) very rapid or slow dark adaptation, (b) very complete or imperfect dark adaptation" (p. 206).

The work of Sir William Abney and his collaborators, and of many other observers, is diametrically opposed to the independence of the luminosity and colour sensations which Dr. Edridge-Green asserts without proof. Dr. William Watson (Proc. Rov. Soc., A, 88, 1913 , p. 404) devoted an exhaustive investigation to this point, with special reference to Dr. Edridg--Green's assertion, and in a subsequent communication (Proc. Roy. Soc., A, 89, 1913, p. 36) he was able to disprove the statement on one of Dr. Edridge-Green's own cases. For a prolonged period experiments by the flicker photometric method were carried out by Sir William Abney, Dr. Watson and myself on nearly all the cases of colour blindness which came under our observation, with results which entirely confirm Dr. Watson's conclusions. For reasons which are fully explained by the Young-Helmholtz theory the relationship between colour perception and brightness perception is more easily demonstrated in the so-called "red-blind group," but with suitably delicate methods it is equally demonstrated to be true of the more common "greenblind "variety and the so-called "anomalous trichomats." Dr. Edridge-Green has never brought forward any experimental evidence to disprove these results, and until he does so no unbiassed critic will be impressed by his ibse dixit.

(To be concluded.) 